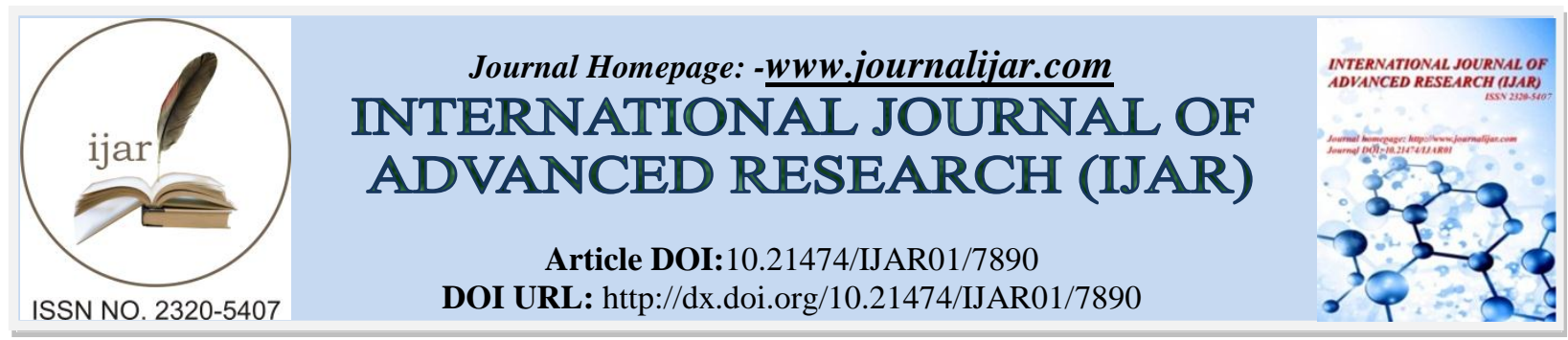

RESEARCH ARTICLE

\title{
STUDIES ON MORPHOLOGY AND MEDICINAL EFFICACY OF NANOPARTICLES SYNTHESIZED FROM TWO MEDICINALLY IMPORTANT CURCUMA SPP., C. LONGA AND C.CAESIA.
}

Minoo Divakaran, Dinsy Mp, Christeena Poulose, Anjali T, Anu P Joy and Anupamavc. Department of Botany, Providence Women's College, Kozhikode 673009. Kerala.

\section{Manuscript Info}

\section{Manuscript History}

Received: 11 August 2018

Final Accepted: 13 September 2018

Published: October 2018

Keywords:-

Curcuma longa, C.caesia, curcumin, nanosynthesis, pellets.

\begin{abstract}
Turmeric,a spice and medicinal plant, has proven to be the most effective nutritional supplement for the human body. The present study made an attempt to compare the morphological and anatomical characterization of two species of Curcuma, to standardize a user ecofriendly protocol for the biosynthesis of silver nanoparticles (AgNPs) through biological method, and to evaluate the antifungal activity of these species. $C$ longa had curcumin cells while C.caesia had no curcumin cells, only starch grains. Ag- nanoparticles were synthesized at a much faster rate in C.longa, when compared to that in C.caesia. Antifungal activity is faster for $\mathrm{AgNO}_{3}$ mixture of C.longa, and much slower in aqueous extract of C.longa and C.caesia and $\mathrm{AgNO}_{3}$ mixture of C.caesia. The fungal colonies were destroyed soon after the colony was inoculated with $\mathrm{AgNO}_{3}$ mixture of C.longa, but no visible change in diameter occurred in the fungal colony after the inoculation of other mixtures. Pellets could be made from powdered rhizomes of both species which could be used as a safe alternative to preventive diseases.
\end{abstract}

Copy Right, IJAR, 2018,. All rights reserved.

\section{Introduction:-}

Medicinal plants play an important role in the development of potent therapeutic agents. Herbal medicines are currently in demand and their popularity is increasing day by day hence it plays a vital role for the development of new drugs. Herbal medicines have a vital role in the prevention and treatment of various diseases. Man since time immemorial has been using plants or natural product as medicine to promote and maintain good health (Parrota, 2001). Over the past few decades, there has been increased reports on the biological activities of turmeric, along with their medicinal uses (Sarker and Nahar, 2007) Curcuma longa and C. caesia are two medicinally important species belonging to the family Zingiberaceae andCurcumin is an important phytochemical seen in the members of the genus Curcuma.

Recently, attention has been paid to utilize eco-friendly and bio-friendly plant based products for the prevention and cure of different human diseases. Most of the people have faith in traditional medicine, particularly plant drugs for their primary health care. Even though these plants are commonly available, the multiple uses of these species have increased its commercial demand, resulting in over-exploitation. The use of nanotechnology for 'phytotherapy' or treatment of various diseases by herbal medicines, including herbal drug delivery where current and emerging nanotechnologies could enable entirely novel classes of therapeutics has been reported. Interestingly, pharmaceutical sciences are using nanoparticles to reduce toxicity and side effects of drugs. The 
biologically synthesized nanoparticles with plant products have better chemotherapeutic effects against microbial diseases. Turmeric is commercially available in different forms along with enhancers like bromelain.

The present study made an attempt to compare the morphological and anatomical characterization of two species of Curcuma, to standardize a user eco-friendly protocol for the biosynthesis of silver nanoparticles (AgNPs) through biological method, and to evaluate the antifungal activity of these species

\section{Materials and Methods:-}

\section{Morphological characterization}

The morphological characters that were observed were scale leaf length, width of scale leaf, width of clump, length of fingerling ,nodal length, intermodal length and color of rhizome

\section{Statistical analysis}

Ten observations were taken and considered to calculate the standard deviation of all the morphological characters..

\section{Anatomical studies}

Rhizomes of C.caesia and C.longa and their available tubers were hand sectioned .The sections were stained using safranine, mounted on a slide and viewed under microscope.

The cortical and stellar characters like epidermal hair, number of epidermal layers, vascular bundles in outer and inner cortex and the curcumin content in both species.

\section{Synthesis of nanoparticles}

Aqueous extracts of C.caesia and C.longa, $2 \mathrm{ml}$ each are taken in separate test tubes. One test solution of both C.caesia and C.longa are kept as control. $10 \mathrm{ml} \mathrm{AgNO}_{3}$ is added to the Aqueous extracts of C.caesia and C.longa separately, the mouth of testtube is covered using silverfoil and left unmdisturbed.The color change is noted periodically.

\section{UV- vis spectroscopy}

The absorbance of $\mathrm{AgNO}_{3}$ mixed solutions is found out with the help of UV-vis spectrometer. The solution is transferred into cuvette and then absorbance is calculated.

\section{Anti fungal activity}

Aqueous extracts and $\mathrm{AgNO}_{3}$ mixtures of C.caesia and C.longa are inoculated into separate fungal colonies to find out their antifungal activity.

\section{Pellatisation}

The shade dried rhizomes of C.caesia and C.longa are powdered and pellatised using a hydraulic press.

\section{Results and Discussion:-}

The present work is a comparative study on morphology and medicinal efficacy of nanoparticles synthesized from two medicinally important Curcuma species C. longa and C.caesia. The present studuy revealed the presence of medically active constituents.

\section{Morphological characterization:-}

The freshly removed clumps of C.caesia and C.longa were used for morphological characterization. Morphological characters of both species showed variations, as in Table 1.

Table 1:-Morphological characterization of C. caesia and C.longa (Fig. 1a, 2a)

\begin{tabular}{|c|c|c|c|c|c|c|c|}
\hline PART & $\begin{array}{l}\text { Scale leaf } \\
\text { Length } \\
(\mathrm{cm}) \pm \mathrm{SD}\end{array}$ & $\begin{array}{l}\text { Scale leaf } \\
\text { Width } \\
(\mathrm{cm}) \pm \mathrm{SD}\end{array}$ & $\begin{array}{l}\text { Width } \\
(\mathrm{cm}) \pm \mathrm{SD}\end{array}$ & $\begin{array}{l}\text { Length of } \\
\text { fingerling } \\
(\mathrm{cm}) \pm \mathrm{SD}\end{array}$ & Colour & $\begin{array}{l}\text { Length of } \\
\text { node } \pm \mathrm{SD}\end{array}$ & $\begin{array}{l}\text { Length of } \\
\text { internode } \pm \\
\text { SD }\end{array}$ \\
\hline $\begin{array}{l}\text { C.caesia } \\
\text { rhizome }\end{array}$ & $1.6 \pm 0.11$ & $0.7 \pm 0.09$ & $16.42 \pm .10$ & $5.21 \pm 0.09$ & $\begin{array}{l}\text { Dark blue } \\
\text { to black } \\
\text { colour }\end{array}$ & $3.36 \pm 0.11$ & $\mathbf{1 . 4 1} \pm 0.11$ \\
\hline
\end{tabular}




\begin{tabular}{|l|l|l|l|l|l|l|l|}
\hline Tuber & -------- & ---------- & $0.59 \pm 0.09$ & $1.02 \pm 0.12$ & Colourless & - & - \\
\hline $\begin{array}{l}\text { C.longa } \\
\text { rhizome }\end{array}$ & $2.05 \pm 0.13$ & $1.7 \pm 0.08$ & $\mathbf{2 4 . 4 9} \pm 0.10$ & $\mathbf{6 . 1 4} \pm .12$ & $\begin{array}{l}\text { Yellow to } \\
\text { pale orange }\end{array}$ & $\mathbf{5 . 7 9} \pm 0.11$ & $0.56 \pm 0.10$ \\
\hline
\end{tabular}

Anatomical characterization : The fingerlings of C.caesia and C.longa of similar size were selected for hand sectioning and stained and viewed under microscope Anatomical characters of both species showed extreme variations as depicted in Table 2.

Table 2:-Anatomical characterization of the two species

\begin{tabular}{|l|l|l|}
\hline Character & C. longa & C.caesia \\
\hline Rhizome & Profusely branched & Limited branches \\
\hline Color of rhizome & Yellow & Dark blue -Black \\
\hline Epidermal hairs & 2- celled lignified & Profuse \\
\hline Epidermis & Single layered & 4-5 layered \\
\hline Outer cortex & 20-30 vascular bundles, collateral, scattered & $15-18$ \\
\hline Curcumin cells & Present - More in inner zone & Almost absent \\
\hline
\end{tabular}

Curcumin cells were found in plenty in C.longa but were totally absent in C.caesia (Fig 1b, 2b). Both schizogenous type (secretory duct originating in the intercalary meristem) and lysigenous type (formation in meristematic and mature parts of rhizomes) have been reported in C.longa (Ravindran et al., 2007)
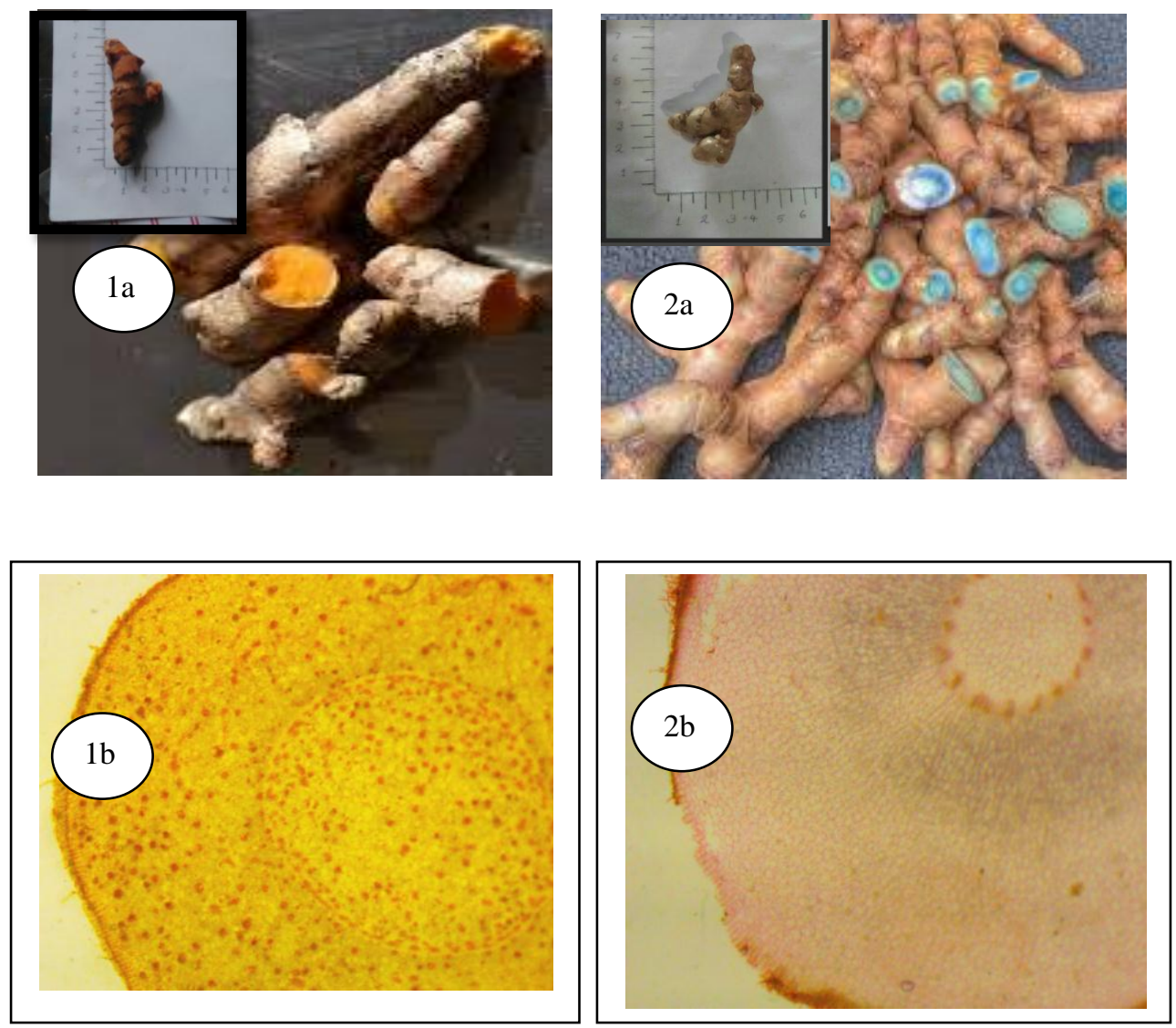

Fig:-1.C.longa a. Rhizome, b. TS of rhizome,

Fig 2:-C. caesia a. Rhizome, b. TS of rhizome 


\section{Nanoparticle Synthesis}

$\mathrm{C}$ longa, C.caesia extracts were mixed with $0.1 \mathrm{~N} \mathrm{AgNO}_{3}$ solution, and the change in colour was noted periodically. It was observed that when Curcuma longa ,Curcuma caesia extract is mixed with $0.1 \mathrm{~N} \mathrm{AgNO}_{3}$ solution, a deep reddish brown colour is obtained after 24 hours (Table 3). The colour indicates the formation of $\mathrm{Ag}$ colloid by chemical reduction of $\mathrm{AgNO}_{3}$.

Table 3:-Indications (colour) of Synthesis of Silver Nanoparticles

\begin{tabular}{|l|l|l|l|l|l|}
\hline Day & TIME & \multicolumn{2}{l|}{ Curcuma longa (Yellow Turmeric) } & \multicolumn{2}{l|}{ Curcuma caesia (Black Turmeric) } \\
\cline { 3 - 6 } & $\begin{array}{l}\mathrm{AgNO}_{3} \\
\text { Control }\end{array}$ & $\begin{array}{l}\text { Light brown } \\
(+)\end{array}$ & $\begin{array}{l}\text { Yellowish grey colour } \\
(+)\end{array}$ & $\begin{array}{l}\text { Ash colour } \\
(+)\end{array}$ & $\begin{array}{l}\text { Ash colour } \\
(+)\end{array}$ \\
\hline 1 & $0 \mathrm{hr}$ & $\begin{array}{l}\text { Yellowish grey colour } \\
(+)\end{array}$ & $\begin{array}{l}\text { Light violet } \\
(++)\end{array}$ & $\begin{array}{l}\text { Ash colour } \\
(+)\end{array}$ \\
\hline 2 & $1 \mathrm{hr}$ & $\begin{array}{l}\text { Coffee brown } \\
(+)\end{array}$ & $\begin{array}{l}\text { Yellowish grey colour } \\
(+)\end{array}$ & $\begin{array}{l}\text { Light violet } \\
(++)\end{array}$ & $\begin{array}{l}\text { Ash colour } \\
(+)\end{array}$ \\
\hline 3 & $4 \mathrm{hrs}$ & $\begin{array}{l}\text { Dark brown } \\
(+++)\end{array}$ & $\begin{array}{l}\text { Yellowish grey colour } \\
(+)\end{array}$ & $\begin{array}{l}\text { Dark violet } \\
(+++)\end{array}$ & $\begin{array}{l}\text { Ash colour } \\
(+)\end{array}$ \\
\hline 4 & $6 \mathrm{hrs}$ & $\begin{array}{l}\text { Dark brown } \\
(++++)\end{array}$ & $\begin{array}{l}\text { Yellowish grey colour } \\
(+)\end{array}$ & $\begin{array}{l}\text { Purple } \\
(++++)\end{array}$ & $\begin{array}{l}\text { Ash colour } \\
(+)\end{array}$ \\
\hline 5 & $24 \mathrm{hrs}$ & Dark brown $(++++)$ & $\begin{array}{l}\text { Brownish grey colour } \\
(+)\end{array}$ & $\begin{array}{l}\text { Grape vine colour } \\
(++++++)\end{array}$ & $\begin{array}{l}\text { Ash colour } \\
(+)\end{array}$ \\
\hline 6 & $36 \mathrm{hrs}$ & Dark brown $(++++)$ \\
\hline
\end{tabular}

\section{UV-Spectroscopy}

The UV-vis spectra recorded on the rhizome extracts mixed with $\mathrm{AgNO}_{3}(3 \mathrm{mM})$ solutions. UV-vis absorption spectra have proved to be quite sensitive to the formation of silver colloids because silver nanoparticle exhibit an intense absorption peak due to surface excitation. The UV-vis spectra recorded on the rhizome extracts mixed with $\mathrm{AgNO}_{3}(3 \mathrm{mM})$ solution as a function of time of reaction. Immediately after addition of $\mathrm{AgNO}_{3}$ solution to the extract, the colour of clear extract first changed to a ring formations of a reddish brown. At this stage, formation of metal nanoparticles due to reduction was observed. The generations of colour is due to excitations of surface plasmons in a metal nanoparticle. Followed by UV-vis spectroscopy, absorption of Ag-nanoparticles was maximum at $277 . .2 \mathrm{~nm}$ for C.caesia and $363.6 \mathrm{~nm}$ for $C$ longa, (Figs 3, 4, 5) which steadily increased in intensity without showing any shift of the wavelength maximum. This depicts the reductions of silver ion taking place at a faster rate and the completions of reaction. UV-vis absorption spectra have been proved to be quite sensitive to the formations of silver colloids because silver nanoparticle exhibit an intense absorption peak due to surface Plasmon.

Ultraviolet- Visible (UV-Vis) Spectrophotometric Analysis

Fig. 3:- Absorption of C.caesia

\begin{tabular}{|r|r|}
\hline Wave length & \multicolumn{2}{|c|}{ Absorbance } \\
\hline 277.2 & 3 \\
\hline 262.8 & 0.957 \\
\hline 251.6 & 1.015 \\
\hline 255.6 & 0.983 \\
\hline
\end{tabular}

Fig. 4:- Absorption of C.longa

\begin{tabular}{|r|r|}
\hline Wave length & Absorbance \\
\hline 319.6 & 1.653 \\
\hline 337.2 & 1.868 \\
\hline 349.2 & 1.982 \\
\hline 294.8 & 1.006 \\
\hline 363.6 & 2.231 \\
\hline 256.4 & 0.926 \\
\hline 268.4 & 0.855 \\
\hline 282.8 & 0.892 \\
\hline
\end{tabular}

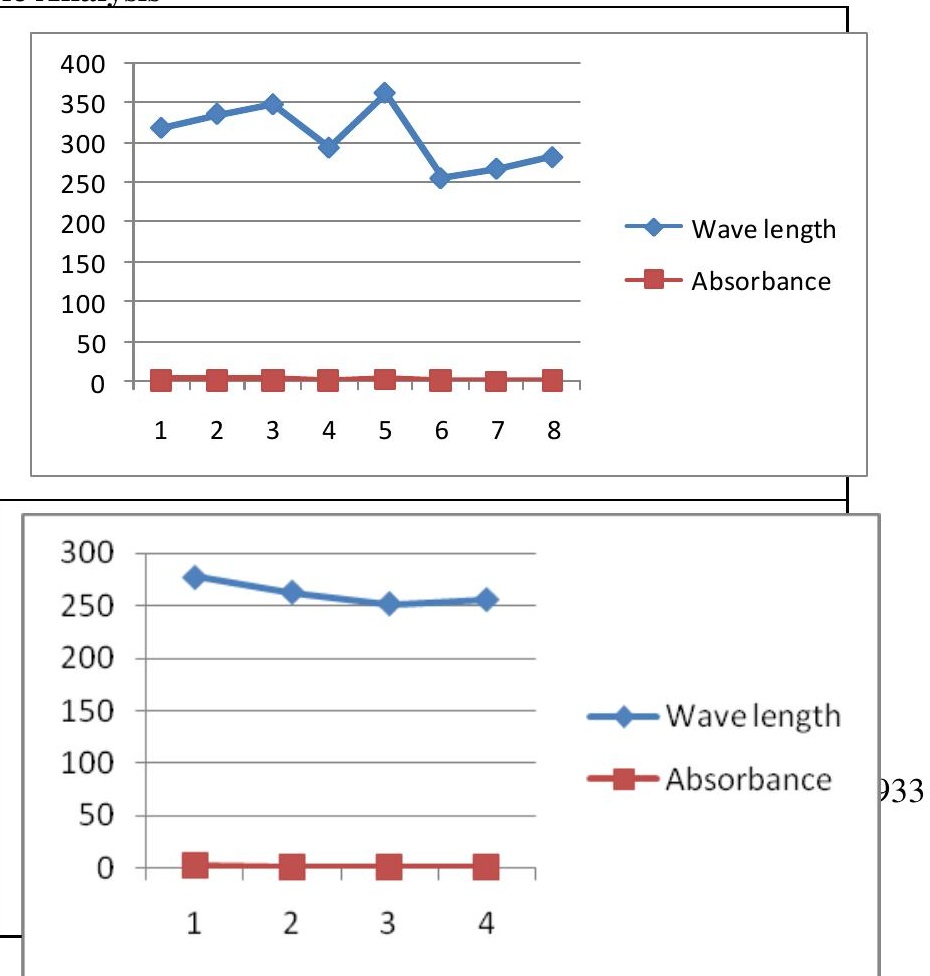




\section{Anti Fungal Activity}

The aqueous and $\mathrm{AgNO}_{3}$ extract of both C.caesia and C.longa were inoculated into fungal colonies grown in petridishes. $\mathrm{AgNO}_{3}$ extract of yellow turmeric killed the fungal colonies immediately after inoculation (Fig 5 ).
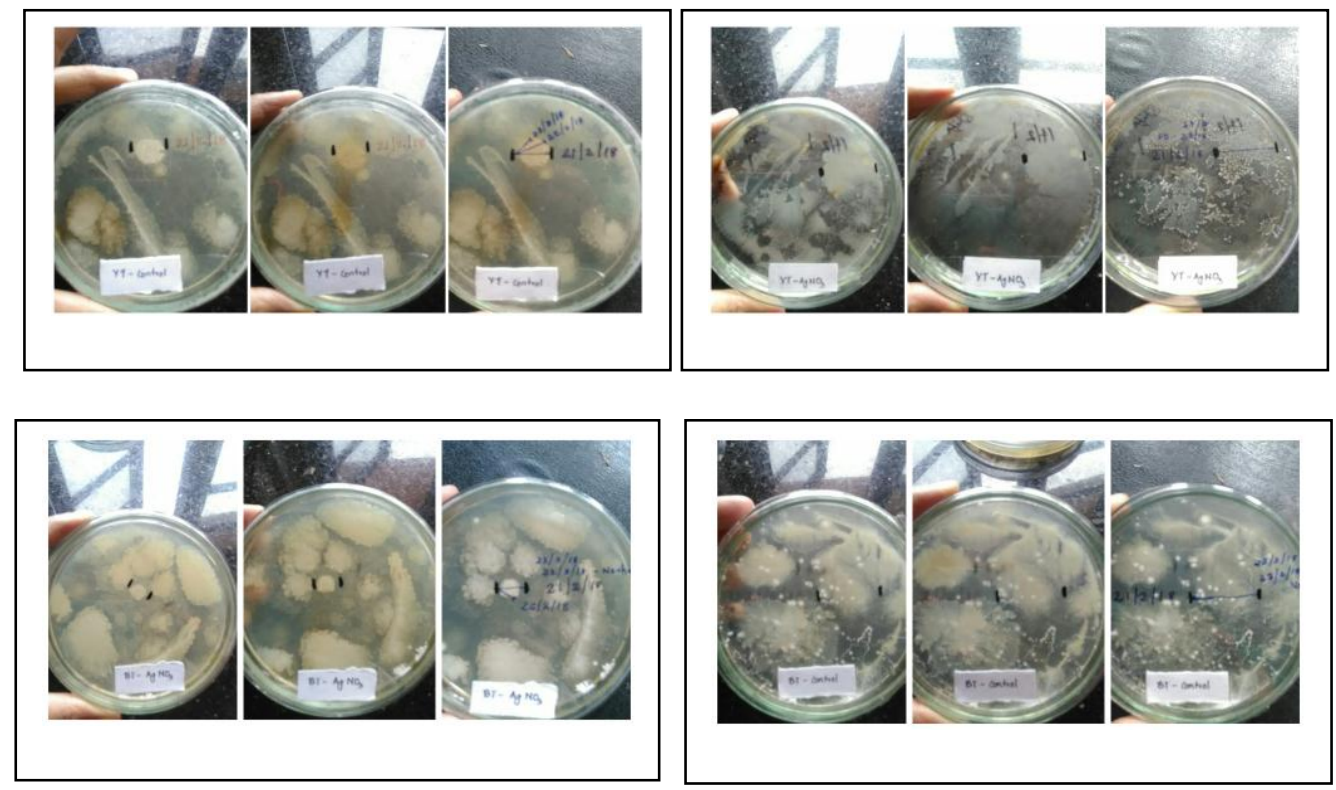

Fig 5:-Antifungal activity of Curcuma species

\section{Preparation of pellets from rhizomes}

The rhizomes of both C.caesia and C.longa were taken, sliced separately and dried in shade. The dried specimens were powdered thoroughly and kept in two separate bottles. Powders are weighed, wrapped in a tissue paper and made into pellets. These pellets can be used as medicinal supplements.

The rhizomes of black turmeric and yellow turmeric with almost equal width are taken ,sliced separately and dried in shade. The dried specimens are powdered thoroughly and kept in two separate bottles. $0.05 \mathrm{~g}$ of black turmeric powder is weighed out. The same procedure is repeated in the case of yellow turmeric powder. The powdered form of specimen is changed to pellets form with the help of pellatizer A pressure of 3ton was applied during the preparation of each pellets.

The pellatizer or Hydraulic press works according to Pascal's Law 'In any fluid the static pressure is exerted on the walls of the container and in the fluid. These forces act perpendicular to the walls of the container.

The press is capable of producing maximum pressure upto 15 tons. It is compact in construction and occupies only a bench space. Acrylic screens are provided for the safety of the operator. The base plate has provision for bench mounting. They are used to prepare pellets. Pellets could be successfully made (Fig.7) from both species, indicating a viable method for preparation of consumable pellets for routine health care

Antifungal activity of the essential oil of Curcuma caesia was experimented by Banerjee and Nigam (1976). The rhizomes were tested for antifungal activity against several human and plant pathogenic fungi. Dilutions of the oil in ethylene glycol were tested by an agar diffusion procedure on plates seeded with the test isolates. Some antifungal effect was noted, but no consideration was given in designing the experiment to the fact that oil diffused poorly through agar gels. The significance of the results therefore remains unclear. Antimicrobial efficacy of essential oil from Curcuma caesia was done by Garg and Jain, 1998. The essential oil from rhizome of $C$. caesia, rich in curcumene, ionone and turmerone, was tested for antimicrobial activity against Bacillus subtilis Corynebacterium diphtheriae, Staphylococcus aureus, Salmonella typhi, Escherichia coli, Shigella, Aspergillus niger, A. fumigatus, Curvularia lunata Fusarium psidi and Rhizopus oryzae by the paper disc diffusion method. The oil exhibited strong to moderate inhibitory action against all the bacterial and fungal species tested. Betancor-F et al 2003 have reportedly done the screening of pharmaceutical preparations containing extracts of turmeric rhizome, for antioxidant capacity. Lantz et al., 2005 have studied the effect of turmeric extracts 
on inflammatory mediator production. Sharma M et al., 2010. have reported that antifungal curcumin induces reactive oxygen species and triggers an early apoptosis but prevents hyphae development. The leaves of plants like Mentha, Ocimum, and Eucalyptus were reported for the synthesis of gold nanoparticles. The particles were spherical in shape, 3-16 nm, Ocimum leaf provided finer particles compared with other plant leaves used (Jha and Prasad, 2012).

Morphological characters indicated that $C$ longa has larger scale leaf characters in terms of length and breadth, clump width, fingerling length and nodal length, while $C$.caesia has higher intermodal length. $C$ longa had curcumin cells while C.caesia had no curcumin cells. Ag- nanoparticles were synthesized at a much faster rate in C.longa, when compared to that in C.caesia. Absortipon of Ag-nanoparticles was maximum at 277..2 nm for C.caesia and $363.6 \mathrm{~nm}$ for $C$ longa. Antifungal activity is maximum for $\mathrm{AgNO}_{3}$ mixture of $C$.longa, and absent in aqueous extract of C.longa and C.caesia and $\mathrm{AgNO}_{3}$ mixture of C.caesia. The fungal colonies were destroyed soon after the colony was inoculated with $\mathrm{AgNO}_{3}$ mixture of C.longa, but no visible change in diameter occurred in the fungal colony after the inoculation of other mixtures. Pellets could be made from powdered rhizomes of both species which could be used as a safe alternative to preventive diseases.

Fig.6:- Synthesis ofAgnanoparticlesbyCurcuma species
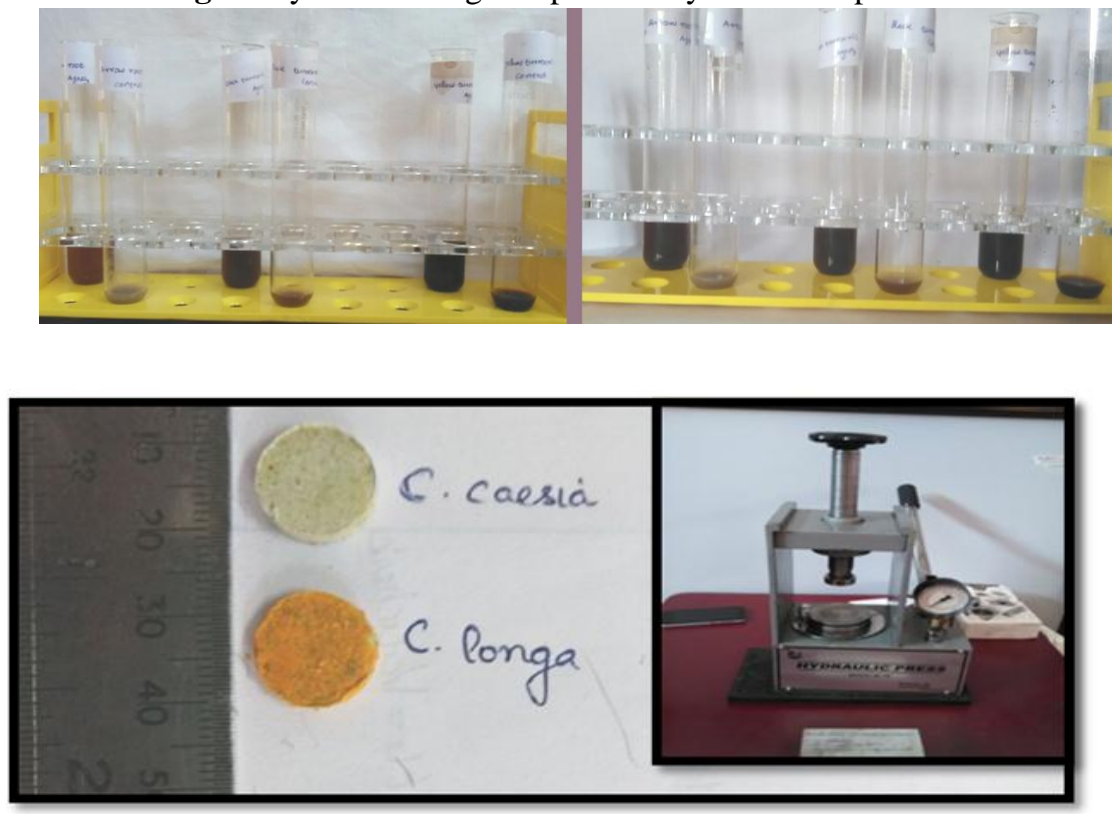

Fig.7:a. Hydraulic Press b.Pelletization of rhizomepowder Curcuma species

\section{Acknowledgements:-}

The authors are highly obliged and grateful to the Principal of the college and the financial support rendered by University Grants Commission (CPE funds), and DST-FIST funds, for taking up these research initiatives. 


\section{References:-}

1. Banerjee A, Nigam SS . 1976. Antifungal activity of the essential oil of Curcuma caesia Roxb. Indian J Med Res. 64(9):1318-21.

2. Betancor-Fernández A, Pérez-Gálvez A, Sies H, Stahl W. 2003. Screening pharmaceutical preparations containing extracts of turmeric rhizome, artichoke leaf, devil's claw root and garlic or salmon oil for antioxidant capacity. J Pharm Pharmacol. 55 : 981-6

3. Garg SC and Jain RK. 1998. Antimicrobial Efficacy of Essential Oil from Curcuma caesia. Indian $J$ of Microbiology. 38 : 169-170

4. Jha, A.K. and K. Prasad. 2012. International Journal of Green Nanotechnology 4(3), 219-224.

5. Lantz R. C, Chen G. J, Solyom A. M, Jolad S. D, Timmermann B. N. 2005The effect of turmeric extracts on inflammatory mediator production. Phytomedicine. 12: 445-52.

6. Ravindran PN, Babu KN and Shiva KN 2007. Botany and crop improvement of Turmeric. pp15-70, In Turmeric - The genus Curcuma, PN Ravindran, KN Babu, K Sivaraman (Eds), Medicinal and Aromatic plants - Industrial Profiles, CRC Press

7. Sarker D S and Nahar L. 2007. Bioactivity of Turmeric. pp 257-296, In Turmeric - The genus Curcuma, PN Ravindran, KN Babu, K Sivaraman (Eds), Medicinal and Aromatic plants - Industrial Profiles, CRC Press, New York

8. Sharma M, R. Manoharlal, N. Puri, and R. Prasad. 2010. Antifungal curcumin induces reactive oxygen species and triggers an early apoptosis but prevents hyphae development by targeting the global repressor TUP1 in Candida albicans. Bioscience Reports, 30(6) : 391-404. 